Check for updates

Cite this: RSC Adv., 2017, 7, 51612

\title{
Synthesis of fluorinated nanoparticles via RAFT dispersion polymerization-induced self-assembly using fluorinated macro-RAFT agents in supercritical carbon dioxide $\dagger$
}

\author{
Anhou Xu, (D)* Quanxuan Lu, Zhiyuan Huo, Jiachen Ma, Bing Geng, Umair Azhar, \\ Luqing Zhang and Shuxiang Zhang*
}

A series of poly(dodecafluoroheptyl methacrylate)- $b$-poly(methyl methacrylate) (PDFMA- $b$-PMMA) diblock copolymer nanoparticles were prepared by reversible addition-fragmentation chain transfer (RAFT) dispersion polymerization of methyl methacrylate (MMA) in supercritical carbon dioxide. Nuclear Magnetic Resonance (NMR) and gel permeation chromatography (GPC) analysis confirmed an efficient and wellcontrolled block copolymerization. As the length of the PMMA block grows from the soluble PDFMA block it eventually becomes insoluble, which drives in situ polymerization-induced self-assembly (PISA). The influences of the length of $\mathrm{CO}_{2}$-philic PDFMA block, $\mathrm{CO}_{2}$-phobic PMMA block and polymerization pressure were investigated in this PISA process. Also spherical nano-objects were formed upon the synthesis of amphiphilic diblock copolymers in situ. It appeared that, as the length of $\mathrm{CO}_{2}$-philic block PDFMA was increased, there was a corresponding decrease in particle size and particle size polydispersity. Scanning electron microscope (SEM) images revealed that, during the microspheres formation, the greater degree of polymerization (DP) of MMA favoured well-controlled monodisperse microspheres.

Received 25th July 2017

Accepted 27th October 2017

DOI: 10.1039/c7ra08202a

rsc.li/rsc-advances
Historically the self-assembly of block-selective solvents based amphiphilic block copolymers into nano-objects has been widely discussed, and this strategy is globally accepted to synthesize block copolymer nano-objects. These self-assembly processes have been achieved usually via two steps: (i) initial molecular dissolution of the copolymer chains and (ii) reduction of the solvency for one of the blocks to drive microphase separation. In principle, such self-assembled species are generated by the post-polymerization processing of mostly amphiphilic diblock copolymers using either a solvent or $\mathrm{pH}$ switch, dialysis, or thin film rehydration. ${ }^{7,8}$ Such protocols are typically performed at very low copolymer concentrations ( $\leq 1 \mathrm{wt} \%$ is common). ${ }^{9}$

Recently, polymerization-induced self-assembly (PISA) has enabled the preparation of block copolymer nano-objects with relatively high block copolymer concentration (10-30 wt\%) based on either emulsion RAFT polymerization or dispersion RAFT polymerization. ${ }^{10-14}$ By following the PISA strategy, a solvophilic macro-RAFT agent-mediated RAFT polymerization under emulsion or dispersion conditions was performed, and highly concentrated block copolymer nano-objects were obtained through a one pot synthesis. ${ }^{15,16}$

Supercritical carbon dioxide $\left(\mathrm{scCO}_{2}\right)$ is an attractive alternative to conventional solvents as a "green" solvent that is readily available, non-flammable, and possesses tunable solvent properties via pressure variation. Most polymers are insoluble
Shandong Provincial Key Laboratory of Fluorine Chemistry and Chemical Materials, School of Chemistry and Chemical Engineering, Shandong Engineering Research Center for Fluorinated Material, University of Jinan, Jinan 250022, China. E-mail: chm_xuah@ujn.edu.cn; fhxzhangsx@163.com

$\dagger$ Electronic supplementary information (ESI) available. See DOI: 10.1039/c7ra08202a 
in $\mathrm{ScCO}_{2}$, while the majority of vinyl monomers tend to be soluble, and hence, $\mathrm{scCO}_{2}$ is a suitable medium for dispersion polymerizations. The use of $\mathrm{scCO}_{2}$ as medium in radical dispersion polymerizations was pioneered by DeSimone and coworkers, ${ }^{17}$ and also explored as medium for synthesis of block copolymer with RAFT polymerization as reviewed by Zetterlund and Howdle. ${ }^{18,19}$ Most attractive features of that process of block copolymer synthesis in $\mathrm{scCO}_{2}$ dispersion are good efficiency, simplicity and solvent-free synthesis of high-purity block copolymers in a one-pot, solvent-free synthesis. In addition, high blocking efficiencies can be achieved even at high conversion and high molecular weight. ${ }^{20}$

A number of groups have examined the general PISA approach for the preparation of soft matter nanoparticles of variable morphology in a range of mediums including polar (alcohols and water most commonly) $)^{13,21,22}$ and non-polar (typically alkanes) solvents. ${ }^{23,24}$ However, attempts to synthesize polymeric particles in $\mathrm{scCO}_{2}$ are few. ${ }^{3,25-27}$ A RAFT dispersion polymerization of MMA stabilized with poly $(1 H, 1 H, 2 H, 2 H$-perfluorooctyl methacrylate) macro-RAFT in $\mathrm{scCO}_{2}$ along with the formation of micrometersize spherical particles has been reported. But the size distribution of polymeric particles was not uniform and ranged between 1 and $6 \mu \mathrm{m} .{ }^{26}$ However, to the best of our knowledge, no monodispersed nano-sized spherical particles were obtained through this process. In this study, fluorinated block copolymers nanoparticles were synthesized by PISA in $\mathrm{scCO}_{2}$ using poly(dodecafluoroheptyl methacrylate-cumyldithiobenzoate) (PDFMA-CDB) macro-RAFT agent as the $\mathrm{CO}_{2}$-philic stabilizer. A series of PDFMA-CDB macro-RAFT agents and PDFMA- $b$-PMMA diblock copolymers with various lengths of PDFMA and PMMA blocks were synthesized via RAFT technique.

\section{Experimental section}

\subsection{Materials}

Dodecafluoroheptyl methacrylate (DFMA) was purchased from XEOGIA Fluorine-Silicone Chemical Co. Ltd (Harbin, China), and methyl methacrylate (MMA, Tianjin Damao Chemical reagent Factory) were distilled under reduced pressure and stored at $0{ }^{\circ} \mathrm{C}$ before use. The initiator 2,2-azobisisobutyronitrile (AIBN) was purchased from Kermeland recrystallized from methanol prior to use. Cumyldithiobenzoate (CDB) as the RAFT agent was synthesized according to the published literature. ${ }^{28}$ All other chemical agents were used directly. Methanol and tetrahydrofuran (THF) solvents of analytical purity were used as received.

\subsection{Synthesis of fluorinated macro-RAFT agent}

The fluorinated macro-RAFT agent PDFMA-CDB was synthesized via RAFT polymerization. The typical PDFMA-CDB macroRAFT agent was prepared as follows: a solution of DFMA (10 g, $0.025 \mathrm{~mol}), \operatorname{AIBN}\left(0.027 \mathrm{~g}, 1.7 \times 10^{-4} \mathrm{~mol}\right), \operatorname{CDB}(0.227 \mathrm{~g}, 8.3 \times$ $\left.10^{-4} \mathrm{~mol}\right)$ and THF $(10 \mathrm{ml})$ was added to a $50 \mathrm{ml}$ vial equipped with a magnetic stirrer, and degassed with three cycles of freezing-pump-thawing to remove oxygen. The reactor was purged with nitrogen, and then placed in a water bath at $70{ }^{\circ} \mathrm{C}$ with continuous stirring. After $8 \mathrm{~h}$, the vial was cooled in an ice- water bath to terminate the polymerization process. The product was purified by precipitating into excess methanol (three times), yielded a pink powder after drying in a vacuum oven for $24 \mathrm{~h}(8.80 \mathrm{~g}, 85.7 \mathrm{wt} \%$ yield$)$.

\subsection{Synthesis of fluorinated diblock copolymer nanoparticles via RAFT dispersion PISA in $\mathrm{scCO}_{2}$}

The fluorinated diblock (PDFMA- $b$-PMMA) copolymers were prepared by using PDFMA-CDB as macro-RAFT agent. The polymerization was performed in a $50 \mathrm{ml}$ high-pressure autoclave with a magnetic stirrer. The typical diblock copolymer of PDFMA $_{32}-b$-PMMA PM74 $_{74}$ was synthesized as follows. PDFMA ${ }_{32}$ CDB (0.747 g, $\left.5.7 \times 10^{-5} \mathrm{~mol}\right)$, MMA (4 g, $\left.0.04 \mathrm{~mol}\right)$, AIBN $\left(0.0047 \mathrm{~g}, 2.9 \times 10^{-5} \mathrm{~mol}\right)$ were added to a $50 \mathrm{ml}$ autoclave. The autoclave was sealed and degassed with vacuum pump for $3 \mathrm{~min}$ to remove oxygen. Designed amounts of $\mathrm{CO}_{2}$ were then added into the reactor and the system was then heated up to $70{ }^{\circ} \mathrm{C}$. Initial pressures were adjusted between 29 to $30 \mathrm{MPa}$. Polymerizations were stopped after $24 \mathrm{~h}$ by cooling the autoclave to room temperature. After that the autoclave was slowly vented, the final product was obtained as solid blocks/powder (yield close to $100 \%$ ).

\subsection{Procedure for solubility test in supercritical $\mathrm{CO}_{2}$}

Solubility test was carried out in a stainless steel view cell (25.12 $\mathrm{ml}$ ) with two observation windows, which permitted visual observation of the phase behaviour. An accurately weighed amount of polymer $(0.150 \mathrm{~g} \pm 0.001 \mathrm{~g})$ was added in the autoclave with a magnetic stirrer bar before purging with a slow flow of $\mathrm{CO}_{2}$ for $5 \mathrm{~min}$ to remove any oxygen. The system was heated to the desired temperature and pressurized with $\mathrm{CO}_{2}$ from a syringe pump. The pressure was increased gradually by adding $\mathrm{CO}_{2}$ with a flow rate of $0.10 \mathrm{ml} \mathrm{min}^{-1}$ to $0.20 \mathrm{ml} \mathrm{min}{ }^{-1}$ until a polymer/CO homogeneous phase was observed. Cloud point pressure was obtained by gradually depressurizing the bomb until the polymer precipitated. The process was repeated three times, and an average of the results was taken as the cloud point.

\subsection{Characterization}

${ }^{1} \mathrm{H}$ NMR spectra were measured on Advance III $400 \mathrm{MHz}$ NMR spectrometer (Bruker, Faellanden, Switzerland) in deuterated acetone solvent with tetramethylsilane as the internal standard at room temperature. The number-average molar masses $\left(M_{\mathrm{n}}\right)$, the weight-average molar masses $\left(M_{\mathrm{w}}\right)$ and the molar mass distribution (polydispersity index: PDI $=M_{\mathrm{w}} / M_{\mathrm{n}}$ ) were determined by gel permeation chromatography (GPC) with THF as the eluent at a flow rate of $1.0 \mathrm{ml} \mathrm{min}{ }^{-1}$. The system was equipped with a Waters Model 1525 HPLC pump and a Waters Model 2414 refractive index detector. The morphology of the fluorinated nanoparticles was characterized by scanning electron microscopy (SEM) (S-2500, Hitachi Seiki Ltd., Japan). Samples were mounted on aluminum foil sputter-coated with gold before analysis. The microsphere size $\left(D_{\mathrm{n}}\right)$ and size distribution $\left(D_{\mathrm{w}} / D_{\mathrm{n}}\right)$ was determined by counting at least 100 microspheres from the SEM micrographs by using nano-measurer. 
<smiles>[R1]CC(=O)C(=C)C</smiles>

DFMA

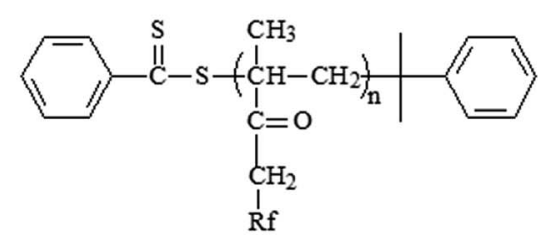

PDFMA $_{m}-\mathrm{CDB}$

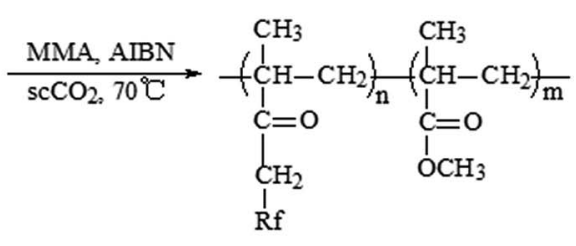

$\mathrm{PDFMA}_{\mathrm{m}}-b-\mathrm{PMMA}_{\mathrm{n}}$

Scheme 1 Synthetic procedures of the fluorinated macro-RAFT agent PDFMA-CDB and PDFMA- $b-M M A$ diblock copolymers.

\section{Results and discussion}

\subsection{Synthesis and characterization of PDFMA-CDB and PDFMA- $b$-PMMA}

A two-step RAFT polymerization was employed for the synthesis of these PDFMA- $b$-PMMA diblock copolymers. Fluorinated macro-RAFT agent, PDFMA-CDB, was synthesized firstly using CDB as chain transfer agent. Then, the prepared macro-RAFT agent was used to obtain a series of diblock copolymers PDFMA- $b$-PMMA via the RAFT dispersion polymerization in $\mathrm{ScCO}_{2}$. In the second step, this fluorinated macro-RAFT agent was acted as both the chain transfer agent and the stabilizer for RAFT dispersion polymerization in $\mathrm{ScCO}_{2}$. The general synthetic procedures are shown in Scheme 1.

The chemical compositions of the fluorinated macro-RAFT agents and PDFMA- $b$-PMMA diblock copolymers were confirmed by ${ }^{1} \mathrm{H}$ NMR spectra. Fig. 1 exhibits ${ }^{1} \mathrm{H}$ NMR spectra of fluorinated macro-RAFT (Fig. 1A) and $\mathrm{PDFMA}_{32}-b-\mathrm{MMA}_{341}$ diblock copolymer (Fig. 1B). It can be seen in Fig. 1A, the signals at 7.10-7.94 ppm are characteristic of the two aromatic ortho to the dithio group, indicating that the RAFT agent moiety remains at the end of the polymer. ${ }^{28,29}$ The signals at 4.52$4.99 \mathrm{ppm}$ are due to the $-\mathrm{O}-\mathrm{CH}_{2}-\mathrm{R}_{\mathrm{f}}$ group of DFMA; and signals at 5.94-6.35 ppm can be assigned to the $-\mathrm{CHF}-$ and $-\mathrm{CH}\left(\mathrm{CF}_{3}\right)_{2}-$ groups. The absorption peaks at about 1.94 and $1.10 \mathrm{ppm}$ are ascribed to $-\mathrm{CH}_{2}-$ repeated units in backbone and $-\mathrm{C}-\mathrm{CH}_{3}$ pendant group in DFMA units. ${ }^{30}$ By comparison with Fig. 1A, clearly, the emergent signals at 3.49-3.74 ppm in Fig. 1B are designated to the $-\mathrm{O}-\mathrm{CH}_{3}$ group of MMA units, ${ }^{31}$ which suggested that the PMMA segments were coupled with PDFMA segments and the block copolymer was achieved.

The time dependence of DFMA conversion and $\ln \left([\mathrm{M}]_{0} /[\mathrm{M}]\right)$ of the polymerization under different DFMA/CDB ratios are shown in Fig. S1. $\uparrow$ The conversion of DFMA increased smoothly with the increase of polymerization time while increased much slightly with the increase of DFMA monomer concentration (or the increase of DFMA to CDB ratio), as shown in Fig. S1(A). $\dagger$ As a result, almost identical DFMA conversion was obtained at the same polymerization time (as shown in Table 1), though the DFMA to CDB ratios distinctly varied. Moreover, it is found that the time dependence of $\ln \left([\mathrm{M}]_{0} /[\mathrm{M}]\right)$ in the polymerization was nearly linear at investigated DFMA to CDB ratios, especially when the polymerization time was less than 8 hours [shown in Fig. S1(B)†], indicates that a living/controlled radical polymerization of DFMA was achieved in the presence of CDB.

In order to investigate the influence of the $\mathrm{CO}_{2}$-philic units, i.e., PDFMA units on the PISA behaviour of the block copolymer PDFMA- $b$-PMMA, fluorinated macro-RAFT agents with different chain lengths were prepared. All the data are listed in Table 1, and the narrow polydispersity indexes (PDI) as shown in Table 1 and Fig. $\mathrm{S} 2 \dagger$ indicate that the polymerizations bear living radical polymerization characteristics. Two methods were used
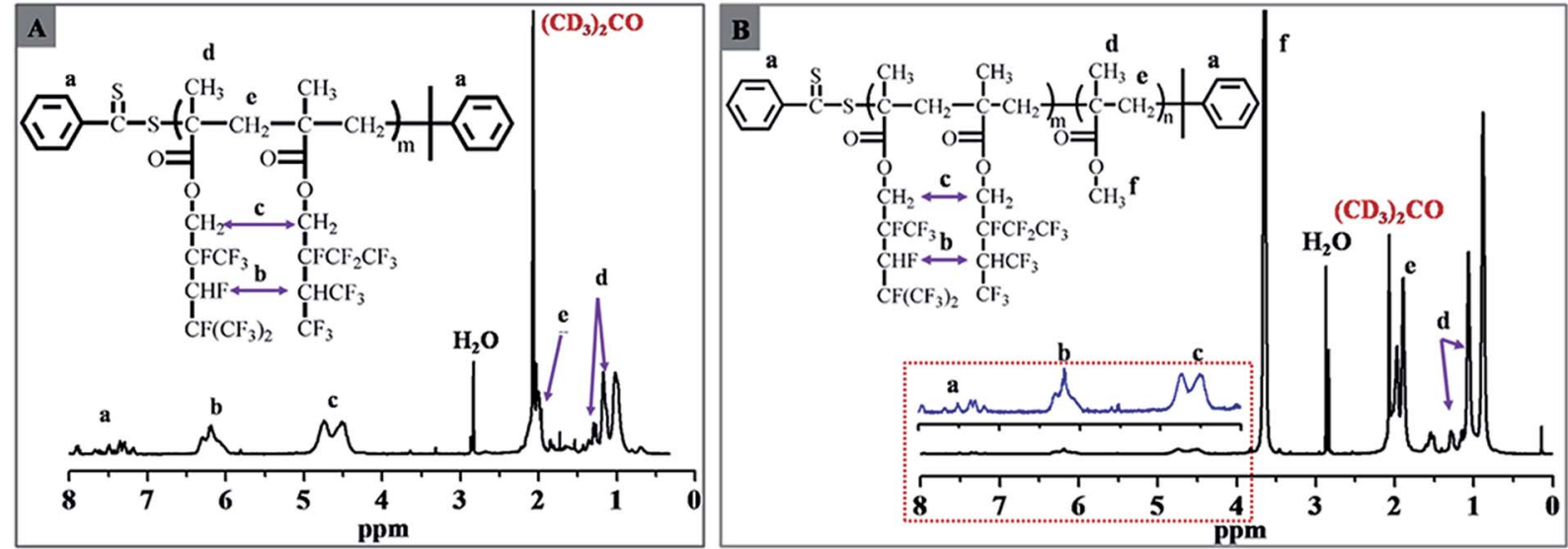

Fig. $1{ }^{1} \mathrm{H}$ NMR spectrum for (A) the fluorinated macro-RAFT PDFMA ${ }_{32}-\mathrm{CDB}$ (Table 1, entry 2) and (B) diblock copolymer PDFMA $32-b-P M M A_{341}$ (Table 2, entry 6). 
Table 1 Molecular weights $\left(M_{n}\right)$ and polydispersity indexes (PDI) of the fluorinated macro-RAFT agents synthesized with RAFT polymerization in $\mathrm{THF}^{a}$

\begin{tabular}{|c|c|c|c|c|c|c|c|c|c|}
\hline Entry & $\begin{array}{l}\text { DFMA/CDB/AIBN composition } \\
\text { (mol\% in feed) }\end{array}$ & Conv. $^{b}(\%)$ & $M_{\mathrm{n}, \mathrm{th}}{ }^{c}$ & $M_{\mathrm{n}, \mathrm{GPC}}{ }^{d}$ & $M_{\mathrm{n}, \mathrm{NMR}}{ }^{e}$ & PDI & $\mathrm{DP}^{f}$ & $\begin{array}{l}\text { Cloud point } \\
\text { (MPa) }\end{array}$ & Sample name \\
\hline 1 & $10 / 1 / 0.25$ & 85.7 & 3700 & 5100 & 6200 & 1.07 & 15 & 7.9 & $\mathrm{PDFMA}_{15}-\mathrm{CDB}$ \\
\hline 3 & $50 / 1 / 0.25$ & 88.9 & 17600 & 11000 & 22000 & 1.12 & 55 & 8.9 & PDFMA $_{55}-\mathrm{CDB}$ \\
\hline
\end{tabular}

${ }^{a}$ The reaction temperature and time are $70{ }^{\circ} \mathrm{C}$ and $8 \mathrm{~h}$ respectively for all experiments. ${ }^{b}$ The conversion was calculated by the weight method.

${ }^{c}$ Determined by the formula: $M_{\mathrm{n}, \mathrm{th}}=\left([\mathrm{DFMA}]_{\mathrm{o}} /[\mathrm{CDB}]_{0}\right) \times M_{\mathrm{DFMA}}+M_{\mathrm{CDB}} \cdot{ }^{d}$ Gel permeation chromatography (GPC) in THF with PS standards.

${ }^{e}$ Calculated by the following equation: $M_{\mathrm{n}, \mathrm{NMR}}=5 \times\left(I_{4.31-4.96} / I_{7.10-7.95}\right) \times M_{\mathrm{DFMA}}+M_{\mathrm{CDB}} \cdot{ }^{f}$ The degree of polymerization (DP) for each polymer was calculated by the ${ }^{1} \mathrm{H}$ NMR spectrum.

Table 2 Experimental conditions and results for the preparation of diblock copolymers with dispersion RAFT polymerization in scCO 2 using different fluorinated macro-RAFT PDFMA-CDB (first block from Table 1) ${ }^{a}$

\begin{tabular}{|c|c|c|c|c|c|c|c|c|c|c|}
\hline Entry & $\begin{array}{l}\text { Monomer/macro-RAFT composition } \\
\text { (mol\% in feed) }\end{array}$ & $\begin{array}{l}\text { Yield } \\
\%\end{array}$ & $M_{\mathrm{n}, \mathrm{th}}^{b}$ & $M_{\mathrm{n}}{ }^{c}$ & PDI & $\mathrm{DP}^{d}$ & $\begin{array}{l}\text { Physical } \\
\text { state }^{e}\end{array}$ & $D_{\mathrm{n}}^{f}$ & $D_{\mathrm{w}} / D_{\mathrm{n}}{ }^{g}$ & Sample name \\
\hline 1 & MMA/PDFMA $15-\mathrm{CDB}=100 / 1$ & 96 & 16272 & 16000 & 1.09 & 98 & SB & n.a. & n.a. & $\mathrm{PDFMA}_{15}-b-\mathrm{PMMA}_{98}$ \\
\hline 3 & MMA/PDFMA $15-\mathrm{CDB}=500 / 1$ & 99 & 56272 & 59500 & 1.42 & 533 & WP & 259 & 1.23 & $\mathrm{PDFMA}_{15}-b-\mathrm{PMMA}_{533}$ \\
\hline 4 & 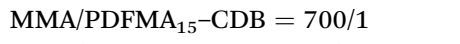 & 99 & 76272 & 74200 & 1.41 & 680 & WP & 171 & 1.10 & PDFMA $_{15}-b-\mathrm{PMMA}_{680}$ \\
\hline 5 & MMA $/$ PDFMA $_{32}-\mathrm{CDB}=92 / 1$ & 98 & 22272 & 23500 & 1.21 & 112 & SB and WP & n.a. & n.a. & PDFMA $_{32}-b-\mathrm{PMMA}_{112}$ \\
\hline 8 & 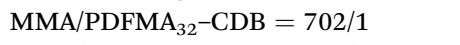 & 100 & 82272 & 89700 & 1.26 & 774 & WP & 153 & 1.06 & $\mathrm{PDFMA}_{32}-b-\mathrm{PMMA}_{774}$ \\
\hline 9 & $\mathrm{MMA} / \mathrm{PDFMA}_{55}-\mathrm{CDB}=100 / 1$ & 98 & 32272 & 31400 & 1.23 & 91 & SB and WP & n.a. & n.a. & PDFMA $_{55}-b-\mathrm{PMMA}_{91}$ \\
\hline 10 & 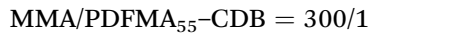 & 99 & 52272 & 58800 & 1.42 & 365 & WP & n.a. & n.a. & PDFMA $_{55}-b-\mathrm{PMMA}_{365}$ \\
\hline 11 & 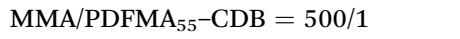 & 99 & 72272 & 71500 & 1.43 & 493 & WP & 81 & 1.09 & PDFMA $_{55}-b-\mathrm{PMMA}_{493}$ \\
\hline 12 & 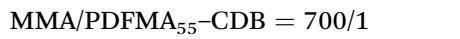 & 100 & 92272 & 108500 & 1.33 & 862 & WP & 102 & 1.08 & PDFMA $_{55}-b-\mathrm{PMMA}_{862}$ \\
\hline
\end{tabular}

${ }^{a}$ Reactions performed with $[\mathrm{MMA}]=0.8 \mathrm{M}$, [PDFMA-CDB] : [AIBN] $=2: 1$, in $50 \mathrm{ml}$ high-pressure autoclave at $70{ }^{\circ} \mathrm{C}$ and $30 \mathrm{MPa}$ for 24 h. ${ }^{b} \mathrm{M}_{\mathrm{n}, \text { th }}=$ $\left(\left([\mathrm{MMA}]_{0}\right) /[\mathrm{PDFMA}-\mathrm{CDB}]_{\mathrm{o}}\right) \times M_{\mathrm{MMA}}+M_{\mathrm{PDFMA}-\mathrm{CDB}} \cdot{ }^{c}$ Gel permeation chromatography (GPC) in tetrahydrofuran with PS standards. ${ }^{d}$ The degree of polymerization (DP) for each polymer was calculated by the GPC. The degree of polymerization of the second block PMMA, DP ${ }_{n P M M A}$ were determined by using the following formula: $\mathrm{DP}_{\mathrm{n}}=\left[\left(M_{\mathrm{n}}\right.\right.$ of diblock copolymer PDFMA- $b$-PMMA $-M_{\mathrm{n}, \mathrm{NMR}}$ of PDFMA-CDB $) /$ molecular weight of MMA monomer]. ${ }^{e}$ Based on the visual observations made immediately after the recovery of the polymers from the reactor, $\mathrm{SB}=\mathrm{solid}$ block, $\mathrm{WP}=$ white powder. ${ }^{f} D_{\mathrm{n}}=$ particle size. ${ }^{g} D_{\mathrm{w}} / D_{\mathrm{n}}=$ size distribution. n.a.: not applicable.

to estimate copolymer molecular weights $\left(M_{\mathrm{n}}\right)$ : NMR $\left(M_{\mathrm{n}, \mathrm{NMR}}\right)$ and GPC $\left(M_{\mathrm{n}, \mathrm{GPC}}\right)$. The $M_{\mathrm{n}, \mathrm{NMR}}$ of PDFMA was calculated from the integration areas of $\mathrm{CH}_{2}$ absorptions $\left[-\mathrm{O}-\mathrm{CH}_{2}-\mathrm{R}_{\mathrm{f}}(4.52-\right.$ $4.99 \mathrm{ppm})]$ of DFMA and that of the aromatic protons (7.10-7.94 $\mathrm{ppm}$ ) of CDB in the ${ }^{1} \mathrm{H}$ NMR spectrum. $M_{\mathrm{n}}, \mathrm{GPC}$ were consistently lower than those calculated by NMR. The difference $M_{\mathrm{n}},_{\mathrm{GPC}}$ and $M_{\mathrm{n}, \mathrm{NMR}}$ (especially entry 3 ), might be due to the inadequate solubility of these fluorinated macro-RAFTs in THF or due to the different molecular structure of these prepared fluoropolymers with standard samples of PS in GPC. By giving the inadequacy of GPC for these calculations, NMR was determined to be the best estimate of the degree of polymerization (DP) for each PDFMACDB homopolymer was calculated by $M_{\mathrm{n}, \mathrm{NMR}}$.

One of the most important features of the RAFT process is its ability to reinitiate the polymer chain to continue propagation in the presence of a second monomer, hence the capacity to produce a range of block copolymers increases. A series of PDFMA- $b$-PMMA diblock copolymers were subsequently prepared by using the synthesized fluorinated macro-RAFT agents in $\mathrm{scCO}_{2}$, the results of which are summarized in
Table 2. Analysis on the GPC after chain extension shows unimodal systems for the diblock copolymers PDFMA- $b$-PMMA with the loss of the peak for PDFMA-CDB samples, which shows that the fluorinated macro-RAFT PDFMA-CDB effectively acted as a macro chain transfer agent. All the reactions were completed after $24 \mathrm{~h}$. Monomer conversion (MMA) was nearly quantitative. Additionally, unimodal GPC chromatograms smoothly shifted towards the higher molecular weight side with increasing DP of the second block PMMA with no trace from unreacted macro-RAFT or bimolecular termination (Fig. 2, S3 and $\mathrm{S} 4 \dagger$ ). Importantly, these chain extended species, i.e., diblock copolymers PDFMA- $b$-PMMA showed relatively narrow PDIs $(<1.5)$ and reasonable agreement with the theoretical molecular weight $\left(M_{\mathrm{n}, \mathrm{th}}\right)$. The results of all characterizations confirmed the successful synthesis of the PDFMA- $b$-PMMA diblock copolymers in $\mathrm{scCO}_{2}$ (as shown in Table 2).

\subsection{PISA of PDFMA-b-PMMA diblock copolymer in $\mathrm{scCO}_{2}$}

Supercritical $\mathrm{CO}_{2}$ is a good solvent for most liquid vinyl monomers, and a poor solvent for most polymers except for 


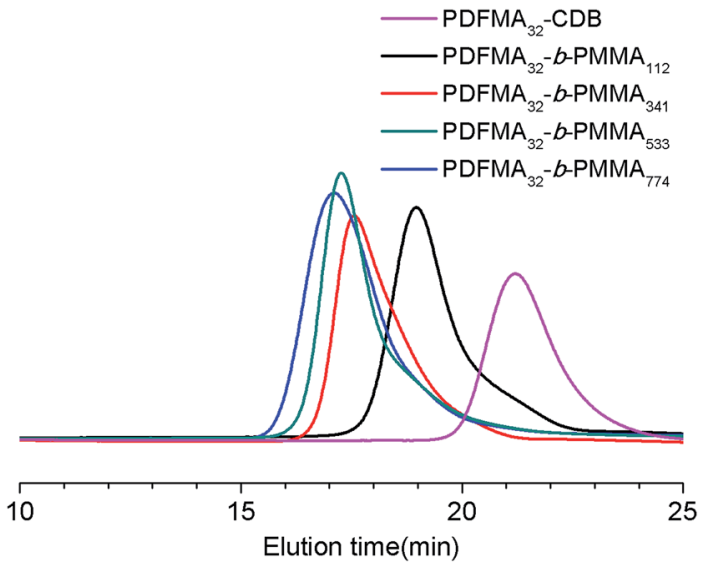

Fig. 2 GPC traces of the PDFMA $A_{32}-C D B$ homopolymer (Table 1, entry 2) and $P_{D F M A}-b-P_{32} M M A_{n}$ diblock copolymers.

some fluoropolymers, poly(siloxanes), and poly(ethercarbonate) copolymers. ${ }^{17,32}$ The fluorinated macro-RAFT agent, PDFMA-CDB, with different molecular weights (DP $=15,32$ and 55) was used in this study otherwise mentioned. It was also acted as stabilizer in the formation process of fluorinated nanoparticles. When the polymerization with a feed molar ratio of PDFMA-CDB/MMA/AIBN = $10: 5000: 1$ was carried out in $\mathrm{ScCO}_{2}$ at $70^{\circ} \mathrm{C}$ and $30 \mathrm{MPa}$ (Table 2, entry 1 ), a clear transition of polymerization solution from transparent to opaque were observed due to formation of aggregates. The aggregates were spherical particles with PMMA core and PDFMA corona (Scheme 2), due to the soluble nature of PDFMA in $\mathrm{scCO}_{2}$ while PMMA remained insoluble. Fluorinated PDFMA- $b$-PMMA copolymer particles having uniform particle diameters ranged from about $80 \mathrm{~nm}$ to $300 \mathrm{~nm}$ were prepared by tuning the length of $\mathrm{CO}_{2}$-philic PDFMA block, $\mathrm{CO}_{2}$-phobic PMMA block and polymerization pressure. Nanoparticle structures have been previously observed upon changing the relative mass fraction of the constituent blocks. ${ }^{3}$ The length of $\mathrm{CO}_{2}$-philic fluorinated macro-RAFT agent, mass fraction of the constituent blocks and selective $\mathrm{CO}_{2}$ solvent have also strongly influence on these segregation behavior of block copolymer phase, resulting in nano-sized particle morphologies that are different from those observed for micro-sized polymer particles formed in conventional dispersion polymerization in $\mathrm{ScCO}_{2} \cdot{ }^{3,25,27}$

3.2.1 Effect of PMMA block length at a fixed length of fluorinated macro-RAFT. In this section, it was studied that how the morphology of diblock copolymer products were changed with the length of the PMMA block ( $\mathrm{CO}_{2}$-phobic), keeping the fluorinated macro-RAFT length constant. Descriptions of the physical state based on the visual observation of the products immediately after the recovery of the copolymers from the reactor are summarized in Table 2. Three types of resulting products were obtained depending on the length of the $\mathrm{CO}_{2}$ phobic PMMA block. When the fluorinated macro RAFT agent PDFMA-CDB with DP $=15$ was employed, the copolymerization of MMA in $\mathrm{ScCO}_{2}$ with short PMMA block length yielded solid blocks (Table 2, entry 1). As the PMMA block length was increased in the PDFMA- $b$-PMMA diblock copolymer, the product was obtained as the mixture of white powder and solid block (Table 2, entry 2). By further increasing the PMMA block length, diblock copolymers were obtained as a free flowing white powder from the reactor cell, indicating that successful stabilization of the colloidal dispersion occurred throughout the course of the reaction. Similar observations were also made for PDFMA $_{32}-b$-PMMA $A_{x}$ and PDFMA $_{51}-b$-PMMA $A_{x}$ diblock copolymers as shown in Table 1 . Such apparent physical state changes of the resultant products should be ascribed to the PMMA block length and their aggregation level in $\mathrm{scCO}_{2}$ solvent. Since PMMA is insoluble in $\mathrm{Sc}^{-} \mathrm{CO}_{2}$, when the chain

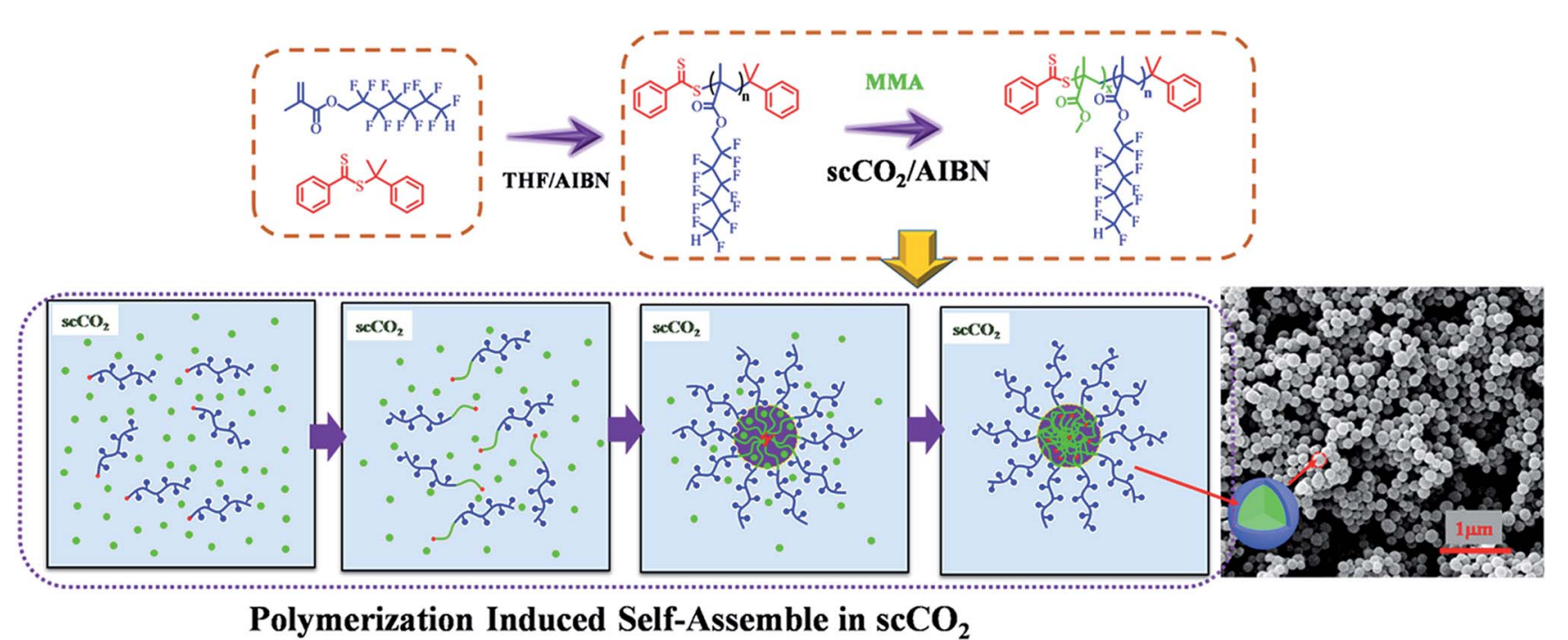

$$
\mathrm{CO}_{2} \text {-philic macro-RAFT agent: ชุ }
$$

Scheme 2 Schematic representation of the general strategy for making fluorinated nanoparticles via RAFT dispersion polymerization-induced self-assembly using fluorinated macro-RAFT agents in supercritical carbon dioxide. 
lengths of the PMMA chain increases past a critical value, a microphase separation occurs to form spherical aggregates with PMMA cores stabilized by the PDFMA (Scheme 2).

According to the literature, ${ }^{33,34}$ fluorinated polymers exhibit high solubility (>10 wt\%) at $25-65{ }^{\circ} \mathrm{C}$ under $35 \mathrm{MPa}$, such as polyfluoroacrylates or polyfluoroethers. On the contrary, other hydrocarbon-based polymers except some poly(propylene oxide) (PPO)-based oligomers or poly(ethylene oxide) (PEO)-based oligomers show solubility lower than $0.1 \mathrm{wt} \%$ (or completely insoluble) even at the molecular weight as low as 1700 , such as polystyrene, poly(methyl methacrylate), etc. In this study, the solubility of fluorinated macro-RAFT agents and diblock copolymers was measured in $\mathrm{CO}_{2}$ at temperatures of $70{ }^{\circ} \mathrm{C}$ and pressures ranged from 7.5 to $35 \mathrm{MPa}$. As shown in Table 1, for fluorinated macroRAFT agents, PDFMA $_{n}-\mathrm{CDB}$, the cloud point pressures are in range of 7-9 $\mathrm{MPa}$ and it shows that these fluorinated homopolymers have good solubility in $\mathrm{scCO}_{2}$. Though, fluorinated macroRAFT agents are extremely soluble in $\mathrm{scCO}_{2}$, PDFMA- $b$-PMMA diblock copolymers become insoluble with the increasing length of PMMA block. The cloud point pressures of PDFMA- $b$-PMMA diblock copolymers with different block lengths were determined in $\mathrm{scCO}_{2}$ at $70^{\circ} \mathrm{C}$. Only three diblock copolymers with short PMMA block length, PDFMA $_{15}-b$-PMMA ${ }_{98}, \mathrm{PDFMA}_{32}-b-\mathrm{PMMA}_{112}$, and PDFMA $_{55}-b$-PMMA 91 gave cloud point pressure values of 28,33 and $29 \mathrm{MPa}$, respectively, other diblock copolymers did not dissolve completely in $\mathrm{scCO}_{2}$ at $70{ }^{\circ} \mathrm{C}$ even up to $35 \mathrm{MPa}$.

Scanning electron microscope (SEM) images also reveal that, during the microspheres formation, the greater DP of MMA block would favours in the formation of monodispersive polymer nanoparticles (as shown in Fig. 3, S5 and S6†). At short PMMA block lengths, copolymer PDFMA- $b$-PMMA can be dissolved in $\mathrm{ScCO}_{2}$, thus gives to solid block products. As shown in Fig. 3A, the resultant copolymers are constituted by irregularly schistose conglomeration. By increasing the core-forming PMMA block length, PDFMA- $b$-PMMA copolymers became undissolved, leading to phase segregation of the incompatible blocks which resulted in more block chains aggregation and some spherical aggregates (Fig. 3B). When the chain length was much higher than the point at which phase change occurred, aggregation of the PMMA blocks induced the formation of spherical aggregates and the SEM image in Fig. 3C and D demonstrates the formation of the spherical aggregates, which was consistent with previous results reported..$^{35}$ But there was an apparent lack of morphology transition in previous reports, ${ }^{\mathbf{1 3 , 2 3}}$ where a range of nanoparticles with the sphere to worm to vesicle order-order transitions were observed with increasing the length of solvophobic block for a fixed solvophilic block. Such difference might be ascribed to the high miscibility of the PDFMA and PMMA blocks in $\mathrm{ScCO}_{2}$. Enhancement of miscibility between poorly compatible polymers is a well-known phenomenon for blends formation in $\mathrm{scCO}_{2}{ }^{36}$

3.2.2 Effect of the length of fluorinated macro-RAFT agent. The effect of the length of fluorinated macro-RAFT agent was investigated using different DP of PDFMA block. All reactions were performed at $70{ }^{\circ} \mathrm{C}$ and $30 \mathrm{MPa}$. Fluorinated macro-RAFT agents which was acted as chain transfer agent and $\mathrm{CO}_{2}$-philic stabilizer had varying chain length; however, the length of
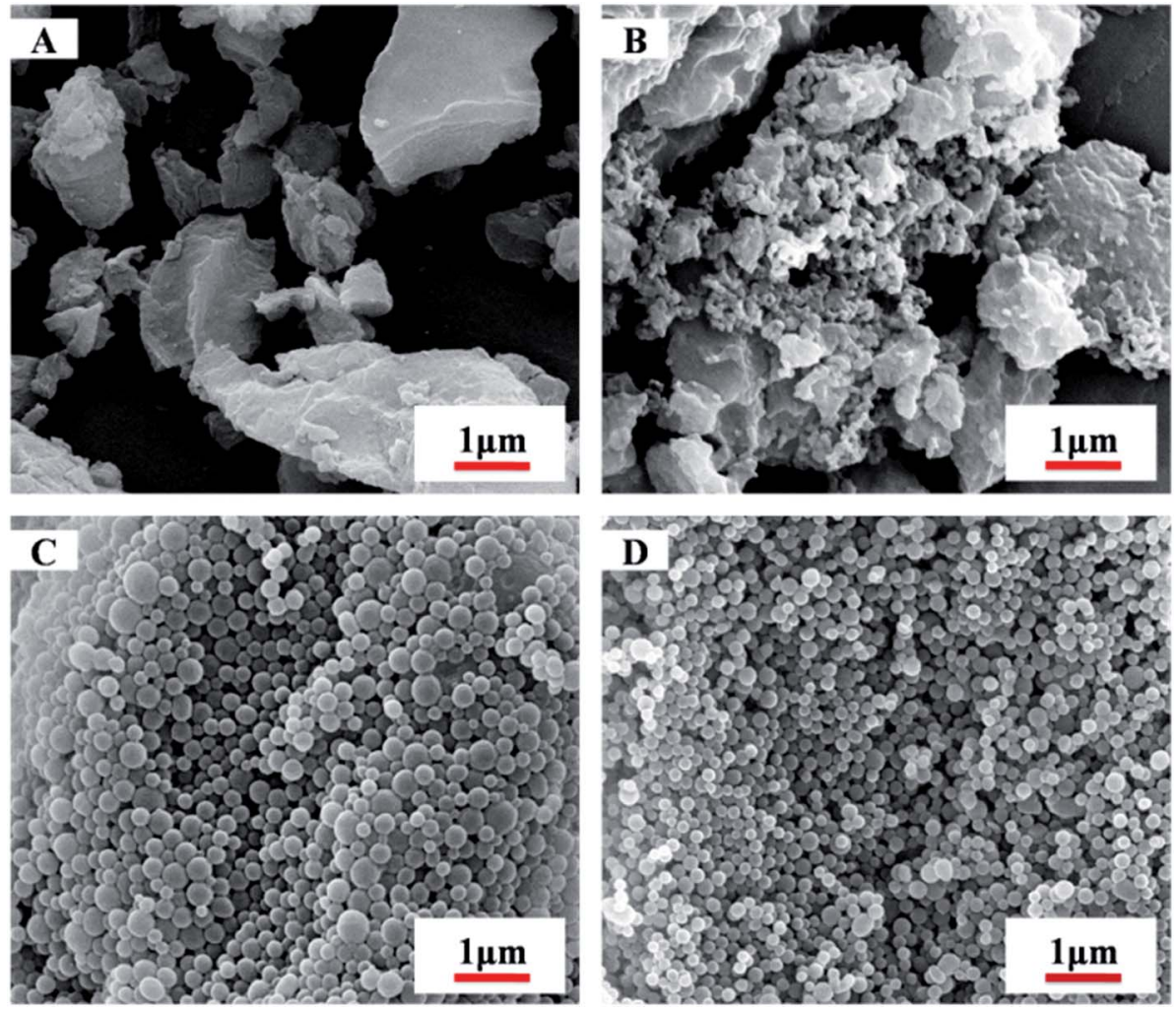

Fig. 3 SEM images of the PDFMA $15-b-\mathrm{PMMA}_{x}$ diblock nanoparticles prepared with RAFT dispersion in sC $\mathrm{CO}_{2}$ using PDFMA $15-C D B$ as a macroRAFT agent: (A): PDFMA $15-b-$ PMMA $_{98}$; (B): PDFMA $15-b-$ PMMA $_{351}$; (C) PDFMA $15-b-$ PMMA $_{533}$; (D): PDFMA $15-b-$ PMMA 680 . 
PMMA block was kept approximately constant. These experiments were performed to demonstrate that it was also possible to control particles size by varying the DP of the $\mathrm{CO}_{2}$-philic block length. The results of these experiments are summarized in Table 2.

As the length of $\mathrm{CO}_{2}$-philic block PDFMA was increased, there was a corresponding decrease in particle size. The morphology change with increasing DP of the fluorinated macro-RAFT was evidenced by SEM as shown in Fig. 4. The particles, though retained narrow particle size distributions, showed decrease in diameter from 259 to $81 \mathrm{~nm}$ when the DP of $\mathrm{CO}_{2}$-philic block PDFMA increased from 15 to 55 . The stabilizer with the longer fluorinated block also led to a narrow particle size polydispersity $\left(D_{\mathrm{w}} / D_{\mathrm{n}}\right)$, which ranged from 1.23 to 1.09 for the PDFMA block with DP of 15 and 55, respectively. This is in agreement with studies involving the synthesis of cross-linked polymer microspheres in $\mathrm{scCO}_{2}$, where it was found that surfactants with longer fluorinated blocks tended to give rise to better particle size control. ${ }^{35}$ These results are also in accord with findings in conventional liquid solvents, where an increase in molecular weight of the polymeric dispersant increases the viscosity of the continuous phase and leads to a more efficient dispersion polymerisation. ${ }^{37}$ This provides better stabilization due to higher equilibrium amounts of stabilizer and a thicker layer of stabiliser on the particle surfaces.

3.2.3 Effect of $\mathrm{CO}_{2}$ pressure. A primary advantage of employing $\mathrm{scCO}_{2}$ as a reaction medium lies in the ability to tune the solvent density and dielectric constant by simply changing either temperature or pressure. This property allows the exploration of solvent effects on a polymerization without need of adding a cosolvent. Fig. 5 shows the variation in morphology for the different pressures: 10,20 and $30 \mathrm{MPa}$. The diameter of the resultant copolymer PDFMA- $b$-PMMA particles increased slightly from 141 to $153 \mathrm{~nm}$ with the polymerization pressure raised from 10 to $30 \mathrm{MPa}$. When initial pressure was $10 \mathrm{MPa}$, the dispersion might be initially stable, but flocculation would occur during the course of the reaction, and the resulting polymer was found to be agglomerated as shown by SEM image

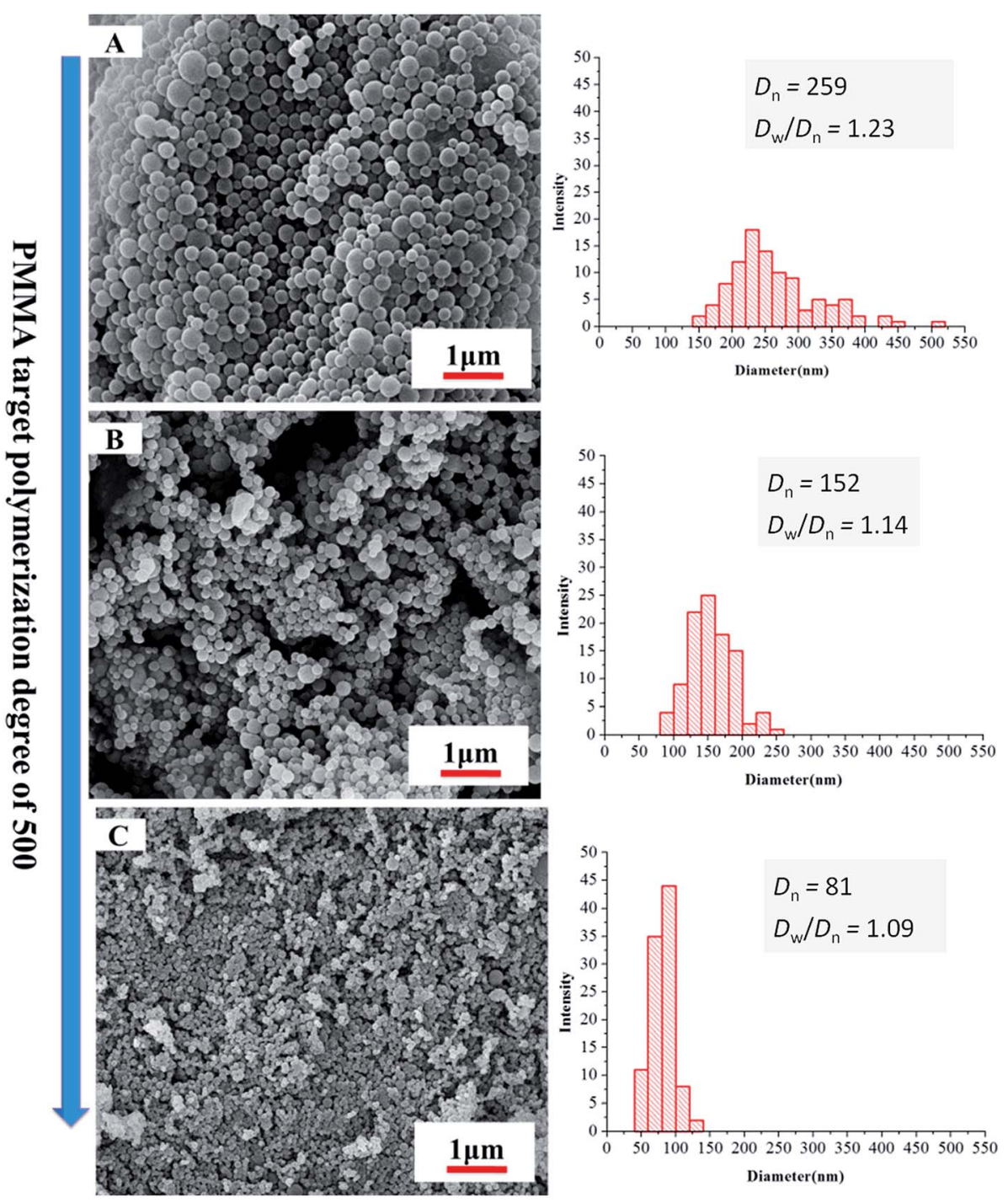

Fig. 4 SEM images of the PDFMA- $b$-PMMA block nanoparticles prepared using PDFMA $A_{n}-C D B$ with variable PDFMA length and with a nearly fixed $\mathrm{PMMA}_{x}$ of 500. (A) PDFMA $15-b-\mathrm{PMMA}_{533}$; (B) PDFMA $32-b-\mathrm{PMMA}_{545}$; (C): PDFMA $55-b-\mathrm{PMMA}_{493}$. 

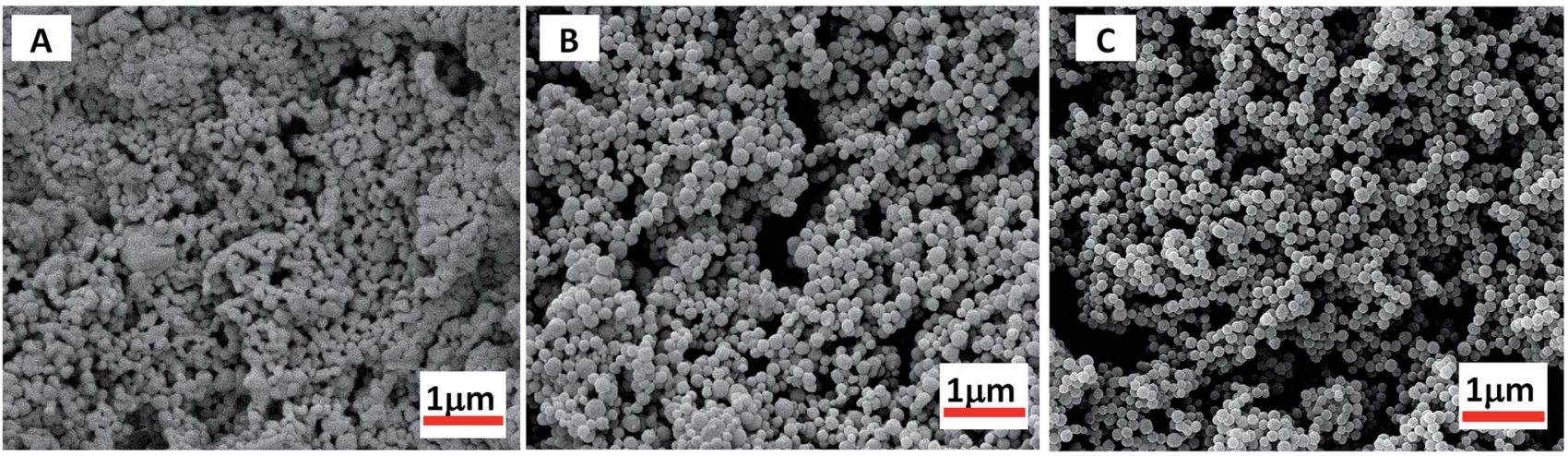

Fig. 5 SEM images of PDFMA- $b$-PMMA block nanoparticles prepared in $\mathrm{scCO}_{2}$ at different polymerization pressure. Reactions performed with $[\mathrm{MMA}]=0.8 \mathrm{M}, \mathrm{MMA} / \mathrm{PDFMA}{ }_{32}-\mathrm{CDB} / \mathrm{AIBN}=692 / 1 / 0.5$ (mol\% in feed) at $70{ }^{\circ} \mathrm{C}$ for $24 \mathrm{~h}$. (A) $10 \mathrm{MPa}$ (B) $20 \mathrm{MPa}$, (C) $30 \mathrm{MPa}$ (entry 8 in Table 1 ).

(Fig. 5A). Simultaneously, the particle size distribution $\left(D_{\mathrm{w}} / D_{\mathrm{n}}\right)$ was narrowed from 1.61 to 1.06 when the initial pressure increased from 10 to $30 \mathrm{MPa}$. As the pressure increased, the solvency of the medium for growing polymer chains were also increased, and this resulted in an increase in critical molecular weight for the microphase of growing oligomeric radicals. ${ }^{38}$ Therefore, the solubility of PDFMA- $b$-PMMA copolymers in $\mathrm{scCO}_{2}$ increases with increasing pressure as result of the increase in $\mathrm{CO}_{2}$ density, leading to well dispersed nanoparticles in $\mathrm{ScCO}_{2}$.

\section{Conclusion}

Herein we have described the synthesis and detailed characterization of fluorinated copolymer diblock nanoparticles based on poly(dodecafluoroheptyl methacrylate)- $b$-poly(methyl methacrylate) (PDFMA- $b$-PMMA) formed in situ via RAFT dispersion polymerization-induced self-assembly using fluorinated macroRAFT agents in supercritical carbon dioxide. It was found that polymeric nanoparticles with different particle size and polydispersity can be prepared by tuning the length of $\mathrm{CO}_{2}$-philic PDFMA block, $\mathrm{CO}_{2}$-phobic PMMA block and polymerization pressure. Results indicate that, by adjusting the polymeric degree of the two segments in diblock copolymer and increase of polymerization pressure, uniform particle size distribution of microspheres can be obtained by polymerization-induced selfassembly in $\mathrm{scCO}_{2}$. The nanoparticles obtained by this strategy are very stable and easy to dry. This method enables various possible paths to study the extensive applications of fluorinated polymeric nanoparticles.

\section{Conflicts of interest}

There are no conflicts to declare.

\section{Acknowledgements}

This work was supported by the National Natural Science Foundation of China (Grant numbers 21304037), Natural Science Foundation of Shandong Province (Grant numbers
ZR2017ZC0529) and the Distinguished Middle-Aged and Young Scientist Encourage and Reward Foundation of Shandong Province (Grant numbers BS2013CL039).

\section{Notes and references}

1 N. Kamaly, B. Yameen, J. Wu and O. C. Farokhzad, Chem. Rev., 2016, 116, 2602-2663.

2 J. Tan, D. Liu, X. Zhang, C. Huang, J. He, Q. Xu, X. Li and L. Zhang, RSC Adv., 2017, 7, 23114-23121.

3 J. Jennings, M. Beija, A. P. Richez, S. D. Cooper, P. E. Mignot, K. J. Thurecht, K. S. Jack and S. M. Howdle, J. Am. Chem. Soc., 2012, 134, 4772-4781.

4 Q. Xiao, J. D. Rubien, Z. C. Wang, E. H. Reed, D. A. Hammer, D. Sahoo, P. A. Heiney, S. S. Yadavalli, M. Goulian, S. E. Wilner, T. Baumgart, S. A. Vinogradov, M. L. Klein and V. Percec, J. Am. Chem. Soc., 2016, 138, 12655-12663.

5 E. Amado and J. Kressler, Soft Matter, 2011, 7, 7144-7149.

6 Y. W. Li, X. W. Zheng, Z. Y. Xia and M. G. Lu, Prog. Org. Coat., 2016, 97, 122-132.

7 X. Wang, G. Guerin, H. Wang, Y. Wang, I. Manners and M. A. Winnik, Science, 2007, 317, 644-647.

8 V. Bütün, S. P. Armes and N. C. Billingham, Polymer, 2001, 42, 5993-6008.

9 Y. Y. Mai and A. Eisenberg, Chem. Soc. Rev., 2012, 41, 59695985.

10 V. J. Cunningham, A. M. Alswieleh, K. L. Thompson, M. Williams, G. J. Leggett, S. P. Armes and O. M. Musa, Macromolecules, 2014, 47, 5613-5623.

11 L. P. D. Ratcliffe, B. E. McKenzie, G. M. D. Le Bouedec, C. N. Williams, S. L. Brown and S. P. Armes, Macromolecules, 2015, 48, 8594-8607.

12 W.-M. Wan and C.-Y. Pan, Polym. Chem., 2010, 1, 1475-1484.

13 Y. Pei, K. Jarrett, L. G. Garces, M. Saunders, J.-P. Croue, P. J. Roth, C. E. Buckley and A. B. Lowe, $R S C A d v$., 2016, 6, 28130-28139.

$14 \mathrm{~J}$. Wu, C. Tian, L. Zhang, Z. Cheng and X. Zhu, RSC Adv., 2017, 7, 6559-6564.

15 S. L. Canning, G. N. Smith and S. P. Armes, Macromolecules, 2016, 49, 1985-2001. 
16 M. J. Derry, L. A. Fielding and S. P. Armes, Prog. Polym. Sci., 2016, 52, 1-18.

17 J. L. Kendall, D. A. Canelas, J. L. Young and J. M. DeSimone, Chem. Rev., 1999, 99, 543-564.

18 P. B. Zetterlund, F. Aldabbagh and M. Okubo, J. Polym. Sci., Part A: Polym. Chem., 2009, 47, 3711-3728.

19 K. J. Thurecht and S. M. Howdle, Aust. J. Chem., 2009, 62, 786-789.

20 J. Jennings, M. Beija, J. T. Kennon, H. Willcock, R. K. O'Reilly, S. Rimmer and S. M. Howdle, Macromolecules, 2013, 46, 6843-6851.

21 A. Blanazs, R. Verber, O. O. Mykhaylyk, A. J. Ryan, J. Z. Heath, C. W. I. Douglas and S. P. Armes, J. Am. Chem. Soc., 2012, 134, 9741-9748.

22 E. T. Garrett, Y. W. Pei and A. B. Lowe, Polym. Chem., 2016, 7, 297-301.

23 L. A. Fielding, M. J. Derry, V. Ladmiral, J. Rosselgong, A. M. Rodrigues, L. P. D. Ratcliffe, S. Sugihara and S. P. Armes, Chem. Sci., 2013, 4, 2081-2087.

24 G. Zheng and C. Pan, Macromolecules, 2006, 39, 95-102.

25 A. M. Gregory, K. J. Thurecht and S. M. Howdle, Macromolecules, 2008, 41, 1215-1222.

26 M. Zong, K. J. Thurecht and S. M. Howdle, Chem. Commun., 2008, 5942-5944, DOI: 10.1039/B812827H.
27 H. Lee, E. Terry, M. Zong, N. Arrowsmith, S. Perrier, K. J. Thurecht and S. M. Howdle, J. Am. Chem. Soc., 2008, 130, 12242-12243.

28 Y. Mitsukami, M. S. Donovan, A. B. Lowe and C. L. McCormick, Macromolecules, 2001, 34, 2248-2256.

29 D. Wan, K. Satoh, M. Kamigaito and Y. Okamoto, Macromolecules, 2005, 38, 10397-10405.

30 Z. Qinghua, Z. Xiaoli, C. Fengqiu, S. Ying and W. Qiongyan, J. Polym. Sci., Part A: Polym. Chem., 2007, 45, 1585-1594.

31 A.-h. Xu, L.-q. Zhang, J.-c. Ma, Y.-m. Ma, B. Geng and S.-x. Zhang, J. Coat. Technol. Res., 2016, 13, 795-804.

32 A. I. Cooper, J. Mater. Chem., 2000, 10, 207-234.

33 M. L. O'Neill, Q. Cao, M. Fang, K. P. Johnston, S. P. Wilkinson, C. D. Smith, J. L. Kerschner and S. H. Jureller, Ind. Eng. Chem. Res., 1998, 37, 3067-3079.

34 E. Girard, T. Tassaing, J. D. Marty and M. Destarac, Chem. Rev., 2016, 116, 4125-4169.

35 W. P. Hems, T.-M. Yong, J. L. M. van Nunen, A. I. Cooper, A. B. Holmes and D. A. Griffin, J. Mater. Chem., 1999, 9, 1403-1407.

36 E. Kung, A. J. Lesser and T. J. McCarthy, Macromolecules, 1998, 31, 4160-4169.

37 C. M. Tseng, Y. Y. Lu, M. S. El-Aasser and J. W. Vanderhoff, J. Polym. Sci., Part A: Polym. Chem., 1986, 24, 2995-3007.

38 P. O'Connor, P. B. Zetterlund and F. Aldabbagh, Macromolecules, 2010, 43, 914-919. 